\title{
A CULTURA INFANTIL RIBEIRINHA: O BRINCAR E OS BRINQUEDOS NO COTIDIANO DA COMUNIDADE DE ARRAIOL/BAILIQUE-AP
}

\author{
PRISCILLA PANTOJA DO NASCIMENTO BRANDÃO* \\ ÂNGELA DO CÉU UBAIARA BRITO**
}

Resumo: o trabalho discute o brincar ribeirinho por meio das práticas culturais das crianças que habitam na comunidade de Arraiol/Arquipélago do Bailique-AP, que contempla os elementos materiais e imateriais presentes no cotidiano deste grupo. Tratase de investigar: como é constituída a cultura infantil que as crianças de Arraiol vivenciam e inventam? Objetiva-se compreender a contribuição do brincar como mediação da cultura infantil ribeirinha por meio da análise do seu cotidiano, identificando sentidos, significados, peculiaridades, que constituem parte do patrimônio cultural para a identidade da comunidade. A metodologia se fundamenta no paradigma qualitativo, no uso da técnica denominada História Oral, que analisa o contexto por intermédio das narrativas dos sujeitos, para compreender os fenômenos sociais em foco por meio das narrativas, mas não somente as vozes, também os gestos, risos, expressões faciais, entre outros, subsidiado nas vivências e registros orais e fotográficos. Utilizou-se no tratamento dos dados a Análise de Conteúdo que consiste em compreender o material que envolve o brincar e as culturas infantis ribeirinhas de Arraiol. Os dados parciais demonstram que o brincar da terra se faz presente no cotidiano da comunidade. Também apresentam índices de que os jogos, brinquedos e brincadeiras tradicionais dos ribeirinhos sofrem modificações ao longo do tempo, mas ainda são formas de mediar o processo de aprendizagem e desenvolvimento da criança por meio das culturas infantis, as quais são características da comunidade ribeirinha que permeia ações através de artefatos sociais e culturais.

Palavras-chave: Brincar. Cultura Infantil. Comunidade ribeirinha.

\section{The riverside children's culture: play and toys in the daily life of the Arraiol community in Bailique-AP}

\begin{abstract}
: this work discusses river play by means of the cultural practices of the children living in the community of Arraiol / Bailique-AP Archipelago, which contemplates the material and immaterial elements present in the daily life of this group. It is a question of investigating: how is the child culture that Arraiol's children experience and invent? The purpose of this study is to understand the contribution of playing as a mediation of the riverside children's culture through the analysis of their daily life, identifying meanings and peculiarities that are part of the cultural heritage for the identity of the community. The methodology is based on the qualitative paradigm, using the technique called Oral History, which analyzes the context through the subjects' narratives, to understand the social phenomena in focus through narratives, but not only the voices, also the gestures, laughter, facial expressions, among others, subsidized in the experiences and oral and photographic records. The Content Analysis was used in the data processing, which consists of understanding the material that
\end{abstract}

\footnotetext{
* Mestranda em Educação do PPGED-UNIFAP.

** Doutora em Educação pela USP e Professora do PPGED-UNIFAP.
} 
surrounds the play and the riverside children's cultures of Arraiol. The partial data show that the play of the land is present in the daily life of the community. They also present indices that traditional games, toys and games of the riverside people suffer modifications over time, but are still ways to mediate the process of learning and development of the child through children's cultures, which are characteristic of the riverside community that permeates actions through social and cultural artifacts.

Keywords: Play. Child Culture. Riverside Community.

\section{Introdução}

O trabalho tem como tema o brincar e a cultura infantil da comunidade ribeirinha de Arraiol, localizada no arquipélago do Bailique/AP, que contempla os elementos materiais e imateriais presentes no cotidiano deste grupo e compreende o tempo histórico dos anos de 2017 e 2018. Compreende-se que o principal direito da criança é o brincar, que lhe oportuniza aprender e desenvolver-se de maneira prazerosa, de forma que a pesquisa propõe investigar a criança e o conhecimento construído social e culturalmente em relação ao brincar, por meio de jogos, brinquedos e brincadeiras que envolvem as culturas infantis do contexto investigado. Desta maneira, indaga-se: como é constituída a cultura infantil que as crianças de Arraiol vivenciam e inventam?

O trabalho traz estudos a respeito do multiculturalismo, e da valorização identitária, que insere um elemento indispensável na infância - o brincar, haja vista que o ambiente característico da Região Amazônica é a Natureza. Torna-se pertinente então, buscar neste fato compreensão de que tal espaço é rico de possibilidades de construção de saberes e experiências, no qual as crianças têm oportunidade de relacionar-se diretamente com os rios, animais, florestas. Trata-se de um ambiente propício à criatividade, no qual as crianças constroem seus próprios brinquedos, jogos e brincadeiras, a partir de galhos, caroços, cipós, folhas, frutos e diversos outros materiais encontrados no ambiente natural em que vivem.

Deste modo, o estudo analisa o brincar que parte das vivências e narrativas relacionadas ao contexto, identificando aspectos relativos à cultura infantil ribeirinha. 0 diálogo que engloba o brincar e a cultura infantil, foi escolhido pela longa história de afinidade por meio de vivências da infância com as comunidades ribeirinhas, também pela grande inquietação trazida a partir de leituras, que mostraram que os estudos nessa área ainda são bastante escassos. 
Baseou-se no quadro teórico para as análises a teoria Histórico-cultural de Lev S. Vygotsky (2007) que trabalha o brincar como fonte e aprendizagem, na criança como sujeito social que aprende com o processo histórico cultural no qual é imersa e no eixo da mediação para a aprendizagem da criança que usa os signos, os instrumentos e artefatos da cultura. Outro eixo de análise sustenta-se na compreensão de que a criança vive a experiência como processo de aprendizagem, fundamentando-se em John Dewey (1976), complementarmente.

Neste estudo, defende-se que a criança deve atuar como sujeito autônomo de seu aprendizado, produzindo conhecimento e cultura, se tiver possibilidades oportunizadas tanto pelos seus pares, bem como pelo meio que a cerca. Tais experiências fazem parte de um processo de desenvolvimento integral da infância, o qual pode ser trabalhado por meio do brincar.

Compreende-se que o trabalho se situa no campo da História da Educação, uma vez que os diálogos envoltos durante todo o estudo, permitem descortinar um mundo rico em detalhes em forma de saberes e fazeres relacionados ao brincar e a cultura infantil, que se constituem como elementos produzidos e modificados socialmente e historicamente, que precisam reconhecidos e valorizados na contemporaneidade.

Metodologicamente, o estudo apoia-se no paradigma qualitativo, no uso da História Oral, que busca analisar o contexto investigado por meio de narrativas, para compreender os fenômenos sociais em foco. Nessa relação combinada Natureza/sociedade, as reflexões que são abertas ao leitor implicam em uma concepção do brincar que traz a experiência como instrumento fundamental na aprendizagem. Utilizou-se no tratamento dos dados a Análise de Conteúdo que consiste em compreender o material que envolve o brincar e as culturas infantis ribeirinhas de Arraiol. Dialoga-se acerca do processo de desenvolvimento integral das crianças e da mediação, sendo o brincar enraizado na cultura e na conexão com a sociedade, que traz como forma de aprendizado o convívio com o meio e a interação social.

Neste sentido, a discussão sobre as culturas infantis torna-se necessária para discutir e revelar aspectos que antes se encontravam na penumbra, na invisibilidade e para contribuir com estudos e pesquisadores da área, fundamentalmente para que esses saberes sejam visualizados e reconhecidos. Desta maneira, compreende-se que os elementos formativos também se constituem a partir de uma ação social de vivên- 
cias empíricas, e não somente conhecimentos científicos.

O trabalho busca apresentar contribuições em forma de diálogos com a teoria, a partir das narrativas e imagens, que trazem a reflexão da importância das culturas infantis na formação da identidade cultural da criança e o seu impacto na vida do ser humano, como um ser socialmente construído. Os desafios para a compreensão deste processo ainda são muitos, porém é necessário que haja concretude na decisão de modificar para melhor a realidade posta, o que leva a compreender que este tema se torna relevante e que acerca desse assunto ainda há muito o que ser discutido.

\section{0 contexto do arquipélago e da comunidade de Arraiol, em Bailique/AP}

Conforme aponta o Instituto Brasileiro de Geografia e Estatística (IBGE), o Arquipélago do Bailique é um distrito do município de Macapá/AP, composto por oito ilhas: Bailique, Brigue, Curuá, Faustino, Franco, Marinheiro, Igarapé do Meio e Parazinho, localizando-se na Foz do Rio Amazonas. Conforme o Censo Demográfico (BRASIL/IBGE, 2010), a população do Arquipélago do Bailique representa $2 \%$ da população do município de Macapá, totalizando 7.618 habitantes.

O Bailique é constituído por florestas de várzea, com as águas do rio de cor barrenta, dono de um ecossistema rico e diverso, característico da Região Amazônica, no qual determinadas áreas são periodicamente imersas pela maré, o que impossibilita o acesso a algumas comunidades em algumas épocas do ano. Os habitantes vivem em palafitas e as ruas das comunidades são a maior parte feitas com pontes de madeira.

As famílias que residem no Arquipélago do Bailique geralmente desenvolvem diversas atividades produtivas, dentre as quais se destacam pesca artesanal e agricultura de subsistência, como a plantação de jerimum, banana, melancia o extrativismo vegetal e, recentemente, a apicultura, mais especificamente no caso da comunidade de Arraiol esta atividade tem crescido bastante. José Cordeiro Lopes, professor e morador da comunidade, teve a iniciativa de escrever um pequeno livro, intitulado "Arraiol do Bailique: uma história de resistência cabocla, no qual evidencia o todo contexto social, cultural, religioso e econômico da comunidade, além de relatar suas diversas conquistas, dentre as quais: 
Depois de participarem de diversos cursos sobre a apicultura, um grupo decide apostar em outra fonte de renda e implantam o primeiro apiário do grupo, utilizando técnicas aprendidas, mas principalmente usando suas próprias experiências e técnicas e a iniciativa deu certo. Hoje, o grupo que começou com quatro caixas de mel tem uma produção que chega a duas toneladas por safra, tem uma marca intitulada 'doce mel' que é reconhecida e que apresenta um produto $100 \%$ natural e de boa aceitação em todo o território (Lopes, 2017, p. 12).

Percebe-se que a comunidade tem almejado seu crescimento econômico, bem como a regularização do trabalho manual, como alternativas de geração de renda. As comunidades do arquipélago são tipicamente comunidades ribeirinhas que vivem em função das águas, das florestas e do plantio na roça. Desse modo, o rio é tanto a fonte de alimentos, bem como a via de transporte dos que ali vivem, e também lugar de lazer para as famílias e do brincar para as crianças, representando a manancial de vida para os moradores.

\subsection{Culturas infantis e o elemento material}

As brincadeiras são manifestações culturais, nas quais a criança expressa suas experiências adquiridas na convivência com o mundo adulto. Ao observar a realização de um jogo, é possível perceber que a criança exterioriza suas vivências, os acontecimentos que fazem parte de sua rotina e isso é um fator preponderante em todas as culturas, destacando a cultura lúdica da população ribeirinha, onde essas experiências cotidianas são fortemente representadas em seus jogos, brinquedos e brincadeiras. Para Tedesco (2006), o ambiente natural em que as crianças ribeirinhas estão inseridas possibilita o desenvolvimento do lúdico por meio do imaginário, repletos de mitos, lentas, crenças, sendo esses saberes transmitidos dos mais velhos para os mais jovens, todos esses fatores relacionados ao seu habitat, se revelam diretamente no brincar.

O fato de conviverem em um ambiente cercado pela natureza, com rios e florestas, faz com que as crianças tenham uma relação íntima com a natureza, uma relação de pertencimento, o que faz com que suas brincadeiras prevaleça a uso de sua imaginação, onde também, seu contexto lúdico "está intrinsecamente ligado aos mitos, lendas e brincadeiras que se originam da água e das riquezas naturais que a cercam. Entender o que representa para ela estes elementos, nos fará compreender seu universo lúdico e sua própria cultura" (Rojas; Ferreira, 2013 P. 10). 
Partindo dessa concepção, considera-se o brincar como um instrumento significativo que possibilita ao sujeito construir conhecimentos, identidade e cultura. No entanto, isso não ocorre de forma igualitária, pois as brincadeiras sofrem variações e se diferenciam conforme o contexto cultural em que os sujeitos estão imersos. Neste sentido, torna-se relevante ressaltar que o Brasil, por possuir uma extensa diversidade geográfica, possui também uma grande diversidade cultural e, portanto, uma variedade de formas de brincadeiras, cada uma com sua especificidade. (Reis et al., 2014).

Desta forma, sendo a brincadeira um elemento culturalmente construído, o brinquedo por sua vez é um objeto fundamental no brincar que é manipulado de diferentes formas pelas crianças e o brinquedo varia de acordo com o ambiente ao qual o sujeito pertence. Ao longo da história o brinquedo encontra-se presente nas mais variadas formas de organização social, política, econômica e cultural e se constitui como um elemento que proporciona momentos de distração, aprendizagem e prazer. (Silva; Carvalho, 2012).

A construção de brinquedo, nos primórdios, era feita de forma manual. Entretanto, com a industrialização, passaram a ser construídos em fábricas com o uso de máquinas e instrumentos industrializados e, assim, passaram a ser produzidos em grande escala, para atender à demanda mercadológica e gerando mais lucros. Neste sentido, os brinquedos industrializados passaram a predominar na sociedade. Todavia, em muitos lugares, ainda prevalece a utilização desses artefatos construídos manualmente, como no caso das comunidades ribeirinhas, que utilizam material artesanal para tal confecção. Oliveira $(1984$, p.18) considera que o brinquedo assim construído, é de grande relevância para a formação social do sujeito, por ser produto da criatividade humana, e não de máquinas. Dessa forma, o autor ressalta que:

\footnotetext{
O fato de o brinquedo artesanal ainda se fazer presente numa sociedade dominada pela automação e, mais recentemente, pela informática testemunha não só o conflito entre polos antagônicos, mas também representa a negação, realizada por artesãos amadores e profissionais, em deixar parecer não apenas brinquedos, mas fundamentalmente, um modo de se expressar no mundo: aquele que resulta da habilidade manual.
}

Nesta perspectiva, o uso dos brinquedos artesanais constitui-se como um elemento mantenedor cultural e se configura como uma forma de resistência à globalização. Desse modo, a confecção manual do brinquedo é fundamental para preservação 
cultural, fazendo com que o sujeito permaneça como parte da sua cultura. Essa forma de confecção, pode ser realizada tanto por adultos, como por jovens e adolescentes que também costumam construir seus próprios brinquedos, dependendo do grau de dificuldade. A criança, ao manuseá-los, passa a atribuir-lhes seus próprios significados, de acordo com a sua imaginação e, nesta perspectiva, os brinquedos são construídos e reconstruídos pelo sujeito, de acordo com seu meio cultural.

Silva (2012) destaca a utilização do fruto do miritizeiro ${ }^{1}$ para a confecção de brinquedos artesanais. Esse material é muito utilizado pelos ribeirinhos, sendo possível construir diversos tipos de brinquedos, como barcos, casas, espingardas, revólveres, dentre outros objetos que variam de acordo com a imaginação de quem está confeccionando. O uso do miriti vem sendo passado de geração para geração e está intimamente relacionado à cultura do caboclo ribeirinho.

De acordo com Loureiro (2012 In Silva, 2012, p. 45), os brinquedos existentes em sua maioria são feitos de miriti, mais precisamente da polpa da bucha de miriti, sendo esta um tipo de palmeira abundante na Amazônia. Assim sendo, é possível afirmar que:

\begin{abstract}
Por compreendermos que o brinquedo de miriti traz em sua constituição aspectos da vida humana como: a ludicidade, a cultura, a religiosidade, a identidade e outros elementos que o tornam mais que um mero objeto de consumo, o tornam um brinquedo que expressa uma forma de ver o mundo e de viver neste mundo.
\end{abstract}

Com base nesta concepção, a utilização do miriti não deve ser considerada apenas como uma representação de objetos, e sim como uma representação cultural das comunidades ribeirinhas, pois através dele os sujeitos representam a realidade do cotidiano do povo em conexão com a Natureza. Estudos realizados por Reis et al. (2014) em uma comunidade ribeirinha, apontam que devido possuírem uma flora e fauna abundante, são muito utilizados recursos naturais para a produção dos brinque-

\footnotetext{
${ }^{1}$ Miritizeiro é o nome popular da árvore, assim como achual, aguaje, buriti, palmeira do brejo, palmeiraburiti. Seu nome científico é Mauritia Flexuosa. A árvore é uma Palmeira que possui de 20 a 40 metros de altura. Abundante nas matas ciliares, várzeas e margens dos igarapés da Região Amazônica. O vegetal tem várias utilidades porque tudo nele é aproveitável. Fornece palha para cobrir cabanas; broto ou grelo para produzir envira, fibra que serve para tecer maqueiras (redes artesanais), tapetes e bolsas; a tala tirada das folhas serve para fazer paneiros tipitis, cestos, balaios e, ainda, brinquedos de formas variadas, como cobras, pombinhas, soca-socas, barcos araras, jacarés e tatus, inclusive miniaturas diversas. (AGA. Artes de Miriti, 2009).
} 
dos. Esses recursos variam desde a utilização de árvores, sementes e folhas, e são comuns para construir brinquedos a serem utilizados durante as brincadeiras que podem ocorrer de diversas formas, tanto em casa, como no rio e até mesmo na mata, no contato direto com a Natureza.

Autores como Reis et al. (2014), indicam ainda que além da utilização do miriti, outros recursos naturais também são utilizados, como as sementes da árvore denominada buiuçu, as quais são chamadas de bole-bole, brincadeira muito comum da cultura ribeirinha, realizada tanto por crianças quanto por adultos; a semente da seringueira também é utilizada nessa brincadeira. Os autores mencionam que a utilização de árvores, como açaizeiros para a construção de jangadas, constitui uma brincadeira de equilíbrio realizada no rio. Usam-se também mangueiras e goiabeiras, como balanços. Há que se registrar ainda a construção de maracá, feito com o ouriço da castanha-doPará, que emite um som e é utilizado até mesmo para representar um instrumento musical. Confeccionam-se gaiolas que podem ser feitas de miriti ou jupati, utilizadas para prender passarinhos, uma prática bastante comum nas comunidades ribeirinhas.

A confecção de bonecas é bastante praticada também na cultura ribeirinha, com as mães utilizando retalhos de tecidos para sua construção, sendo uma prática passada de geração para geração, pois muitas mães ensinam a suas filhas o processo de construção. Reis et al. (2014) ressaltam também em seus estudos, a confecção de bonecas feitas de recursos naturais, como o tronco da bananeira e a utilização das talas de miriti ou de jupati para fazer os membros do corpo da boneca, sendo introduzidos caroços de açaí para representação dos olhos e furos para o nariz e a boca, nas brincadeiras de casinhas feitas por meninos e meninas; utilizam-se folhas para representar as comidas.

Reis et al. (2014, p. 754) enfatizam que "os principais materiais identificados nessa brincadeira foram: palmeira da região, tronco de árvores, a vassoura do açaí, sementes." Desta maneira, essas brincadeiras vão além da representação da vida cotidiana, sendo assim que as crianças expressam seus sentimentos e produzem cultura, relacionando-se com o mundo em que vivem. Considerando esses aspectos, é possível perceber que as brincadeiras realizadas nas comunidades ribeirinhas são reforçadoras de sua cultura, com a utilização de materiais regionais, para construção de brinquedos oriundos da Natureza, onde são mais realizadas tais atividades. 


\section{Percurso Metodológico}

A metodologia utilizada no estudo, alicerça-se no paradigma qualitativo, com caráter descritivo, por meio da técnica denominada História Oral, que conforme Meihy (2002, p. 13), "é um recurso moderno usado para elaboração de documentos, arquivamento e estudos referentes à experiência social de pessoas e de grupos, é sempre uma história do tempo presente e também reconhecida como história viva."

As narrativas foram colhidas por meio de entrevista semiestruturada e não estruturada, com questões referentes aos tipos de brincadeiras e brinquedos, locais para brincar, companhia, fonte de aquisição dos brinquedos e outros, além do registro de fotografias, áudios e filmagens. As fotos e filmagens foram registradas com a devida autorização de cada participante da pesquisa, por meio de Termo de Consentimento Livre e Esclarecido. Os participantes da pesquisa foram as crianças de 0 a 12 anos, seu pais e familiares.

Utilizou-se no tratamento dos dados a Análise de Conteúdo, baseado em Bardin (2016), que consiste em compreender o material que envolve o brincar e as culturas infantis ribeirinhas de Arraiol. Para uma aplicabilidade coerente do método, a pesquisa obedecerá à sucessão das fases de Pré análise, exploração do material, e tratamento dos dados, que no contexto da presente investigação, viabilizam o conteúdo por meio de mensagens faladas ou escritas, verbais ou não verbais, obtidas por meio das entrevistas narrativas e do convívio com a comunidade.

Durante a redação das informações, as pessoas que participarão das entrevistas narrativas serão nomeadas de: “A, B, C, D", e assim em diante, com seus respectivos representantes de acordo com a idade, como por exemplo: se for mulher, "representante mulher de 59 anos", incluindo os homens. Ressalta-se que por se tratar de uma comunidade relativamente pequena, todas as crianças de 04 a 12 anos incompletos foram sujeitos do estudo, atendendo ao princípio da acessibilidade ou conveniência, que diz respeito a quando os participantes estiverem disponíveis e quiserem participar da pesquisa. 


\subsection{Entre saberes, culturas infantis e história: resultados parciais}

Os resultados preliminares foram colhidos a partir do primeiro contato com o locus da pesquisa, por meio de observação diagnóstica, analisaram-se as práticas do brincar desenvolvidas na comunidade, bem como os jogos e os brinquedos construídos. Além da observação e registro de imagens, também foram colhidos relatos, primeiramente com as crianças e posteriormente com adultos.

Observou-se que a comunidade ainda mantém saberes e fazeres que eram realizados por seus antepassados. Assim, o brincar também entra neste conjunto de práticas. Este diagnóstico revelou importantes aspectos de como é o cotidiano das crianças, do que brincam e como vivenciam e inventam essas brincadeiras. Considera-se extremamente importante trazer as imagens dos momentos das crianças em suas brincadeiras, assim como os relatos das vozes dos moradores dialogados com a teoria, pois esses elementos tornam a pesquisa muito mais realista, legítima e dinâmica, comprovando-se também aquilo que se escreve sobre as práticas com aquilo que foi realmente vivenciado no período de estudo neste ambiente.

Para buscar a compreensão do tamanho do espaço que a criança tem hoje na sociedade, se é vista e ouvida, se seu modo de agir e pensar são considerados, se sua própria cultura é valorizada, é necessário compreender qual a importância empregada pelos adultos à infância e como enxergam o brincar. Neste sentido, traz-se a fala de $A$, morador(a) da Representante mulher, de 57 anos, que diz:

\footnotetext{
Não tinha outro brinquedo que a gente pudesse invejar naquela época, porque era aquilo que todas as crianças tinham, e gosto de ver criança brincando, porque eu acredito que a melhor lembrança que a gente guarda com perfeição da vida da gente, é a da infância, quase nada é ruim na nossa infância, tudo é muito gostoso de ser lembrado [...] Não é mais aqueles brinquedos da nossa época, mas eles ainda brincam sim, e muito, as meninas a gente ainda vê, brincando de boneca, brincam bastante, até bem grandinhas mesmo, os meninos são mais a parte de futebol, brincam de montaria, aí pela beira, remando [...] Eles brincam muito com bola, com barquinhos de madeira, pulando na água, nadando, fazem o futi-lama deles na beirada aí, parquinho, pira alta, pira esconde, pira pega, pira ajuda, vôlei, queimada [...] Todas essas brincadeiras. (Lopes, 2017).
}

Neste sentido, para Vigotsky (2007), o brinquedo é um elemento mediador que gera na criança uma Zona de Desenvolvimento Proximal, que é por ele definida como a 
distância entre o nível de desenvolvimento real, que se habitua determinar por meio da resolução autônoma de problemas, e o nível de desenvolvimento potencial, determinado pela solução de problemas sob direção de pessoas mais avançadas ou de um adulto.

É visível que as atividades de movimentos, exploração e experimentação, como as cantigas de roda, as brincadeiras, brincar na lama, contações de histórias, realizadas pelos adultos ou pelas próprias crianças, bem como os jogos, atividades em grupo/compartilhadas, subir em árvores e o faz de conta, proporcionam envolvimento e satisfação para as crianças. Também é pertinente afirmar que as crianças são travessas por natureza, é natural que seus comportamentos sejam bastante agitados, o que lhes ajuda a descobrir cada vez mais e assim adquirir grandes conhecimentos durante 0 processo de desenvolvimento físico e mental.

Os quadros a seguir apresentam os principais jogos e brincadeiras que foram observados e registrados na parte incial desta pesquisa. Estão presentes ainda nos dias de hoje, jogos e brincadeiras que em sua maioria sobreviveram ao tempo e foram perpassados de pai para filho.

Quadro 1 - Jogos e brincadeiras na comunidade ribeirinha de Arraiol/AP (2018)

\begin{tabular}{|c|c|c|c|}
\hline TIPOLOGIA & $\begin{array}{l}\text { PASSAGEM } \\
\text { TEMPORAL E } \\
\text { ESPACIAL }\end{array}$ & SUJEITOS & OUTRAS INFORMAÇÕES RELEVANTES \\
\hline $\begin{array}{l}\text { Brincar na } \\
\text { lama }\end{array}$ & $\begin{array}{l}\text { Antigamente } \\
\text { e hoje }\end{array}$ & $\begin{array}{l}\text { Crianças } \\
\text { e jovens }\end{array}$ & $\begin{array}{l}\text { Fazer bolinhas e jogar uns nos outros, se } \\
\text { enterrar, fazer castelos, esculturas e outros }\end{array}$ \\
\hline $\begin{array}{l}\text { Tomar banho } \\
\text { de rio }\end{array}$ & $\begin{array}{l}\text { Antigamente } \\
\text { e hoje }\end{array}$ & $\begin{array}{l}\text { Crianças, } \\
\text { jovens e } \\
\text { adultos }\end{array}$ & $\begin{array}{c}\text { É tanto uma atividade comum, como uma } \\
\text { brincadeira. Nadar, pular, bater na água, } \\
\text { apostar corrida, etc. }\end{array}$ \\
\hline $\begin{array}{l}\text { Subir em } \\
\text { árvore }\end{array}$ & $\begin{array}{l}\text { Antigamente } \\
\text { e hoje }\end{array}$ & $\begin{array}{l}\text { Crianças } \\
\text { e jovens }\end{array}$ & $\begin{array}{c}\text { Pular de galho em galho, ficar suspensos, } \\
\text { pegar frutos, olhar passarinhos. }\end{array}$ \\
\hline $\begin{array}{l}\text { Andar de } \\
\text { montaria }\end{array}$ & $\begin{array}{l}\text { Antigamente } \\
\text { e hoje }\end{array}$ & $\begin{array}{l}\text { Crianças, } \\
\text { jovens e } \\
\text { adultos }\end{array}$ & $\begin{array}{c}\text { Cotidianamente adultos utilizam a } \\
\text { embarcação, e as crianças imitam por } \\
\text { diversão. }\end{array}$ \\
\hline Bandeirinha & $\begin{array}{l}\text { Antigamente } \\
\text { e hoje }\end{array}$ & $\begin{array}{l}\text { Crianças } \\
\text { e jovens }\end{array}$ & $\begin{array}{l}\text { Há relatos de que a brincadeira é antiga e é } \\
\text { realizada ainda nos dias de hoje }\end{array}$ \\
\hline Futebol & $\begin{array}{l}\text { Antigamente } \\
\text { e hoje }\end{array}$ & $\begin{array}{l}\text { Crianças, } \\
\text { jovens e } \\
\text { adultos }\end{array}$ & $\begin{array}{l}\text { Brincadeira tradicional, onde meninos e } \\
\text { meninas geralmente brincam juntos }\end{array}$ \\
\hline Curralzinho & $\begin{array}{l}\text { Antigamente } \\
\text { e hoje }\end{array}$ & Crianças & $\begin{array}{l}\text { Com bloquinhos de madeira e sementes } \\
\text { variadas }\end{array}$ \\
\hline $\begin{array}{l}\text { Coelhinho sai } \\
\text { da toca }\end{array}$ & $\begin{array}{l}\text { Antigamente } \\
\text { e hoje }\end{array}$ & Crianças & Brincadeira geralmente feita na escola \\
\hline
\end{tabular}




\begin{tabular}{|c|c|c|c|}
\hline $\begin{array}{l}\text { Correr atrás } \\
\text { de cachorro }\end{array}$ & hoje & Crianças & $\begin{array}{l}\text { Brincadeira geralmente realizada por } \\
\text { crianças pequenas }\end{array}$ \\
\hline $\begin{array}{l}\text { Esconde- } \\
\text { esconde }\end{array}$ & $\begin{array}{l}\text { Antigamente } \\
\text { e hoje }\end{array}$ & Crianças & $\begin{array}{l}\text { Brincaderia tradicional perpassada de pai } \\
\text { para filho }\end{array}$ \\
\hline $\begin{array}{l}\text { Cantigas de } \\
\text { roda }\end{array}$ & $\begin{array}{l}\text { Antigamente } \\
\text { e hoje mais } \\
\text { raramente }\end{array}$ & Crianças & Geralmente trabalhadas no ambiente escolar \\
\hline $\begin{array}{l}\text { Correr na } \\
\text { ponte }\end{array}$ & $\begin{array}{l}\text { Antigamente } \\
\text { e hoje }\end{array}$ & Crianças & $\begin{array}{l}\text { Descalças, entre uma brincadeira e outra, em } \\
\text { situações diferenciadas }\end{array}$ \\
\hline Três cortes & hoje & $\begin{array}{l}\text { Crianças } \\
\text { e jovens }\end{array}$ & $\begin{array}{l}\text { Foi observada a brincadeira enquanto as } \\
\text { crianças tomavam banho de rio }\end{array}$ \\
\hline Parquinho & hoje & Crianças & Foi construído pelos adultos para a crianças \\
\hline Queimada & $\begin{array}{l}\text { Antigamente } \\
\text { e hoje }\end{array}$ & Crianças & Ocorre tal qual brincadeira tradicional \\
\hline Bandeirinha & $\begin{array}{l}\text { Antigamente } \\
\text { e hoje }\end{array}$ & Crianças & Brincadeira original frequente \\
\hline Estafete & $\begin{array}{c}\text { Antigamente } \\
\text { e hoje mais } \\
\text { raramente }\end{array}$ & $\begin{array}{l}\text { Crianças } \\
\text { e jovens }\end{array}$ & Jogo de disputa por meio da velocidade \\
\hline Fut-lama & $\begin{array}{l}\text { Antigamente } \\
\text { e hoje }\end{array}$ & $\begin{array}{l}\text { Crianças } \\
\text { e jovens }\end{array}$ & Variação do futebol \\
\hline Uruá & $\begin{array}{c}\text { Antigamente e } \\
\text { hoje mais } \\
\text { raramente }\end{array}$ & $\begin{array}{c}\text { Crianças, } \\
\text { jovens e } \\
\text { adultos } \\
\end{array}$ & $\begin{array}{l}\text { Brincadeira tradicional também realizada em } \\
\text { festividades da comunidade }\end{array}$ \\
\hline
\end{tabular}

Fonte: Elaborado pela autora, com base nos dados da pesquisa.

Verifica-se com base no Quadro 1 a presença de muitos elementos extraídos da terra. As crianças de hoje ainda se instruem das brincadeiras tradicionais porque aprendem com seus pais ou com outro adulto como eram feitos os brinquedos de sua época, e a partir disso, vão modificando os jogos e brincadeiras que Ihes são ensinados. As crianças brincam de tudo, com isopor, sacolas, objetos, por mais simples que sejam, e qualquer elemento material que esteja a seu alcance.

Nesse contexto inicial de pesquisa, percebeu-se que a comunidade ainda apresenta jogos e brincadeiras tradicionas que são peculiares e que dialogam com o espaço natural de vivências daqueles que ali habitam, assinalando um processo de resistência e valorização cultural dos saberes e fazeres que vão se ressignificando ano após ano. Alguns desses jogos e brincadeiras foram vistos com mais frequência no cotidiano do grupo, como por exemplo: Jogo de Futebol, Brincadeira na Lama, Subir em árvores, Curralzinho, Bandeirinha, Três cortes, dentre outros. Já no que se refere às 
brincadeiras que não foram observadas durante os primeiros contatos, foram: Uruá, Estafete e Cantigas de roda, que só foram registradas por conta dos relatos dos adultos, mas isso não quer dizer que na continuação da pesquisa não serão vistas; é necessário estudos mais aprofundados para essa constatação, assim como o quadro pode ser ampliado com mais informações de situações lúdicas, pois as observações preliminares aconteceram no período de transição do inverno para o verão.

Nesta direção compreende-se que os jogos e brincadeiras presentes no cotidiano da comunidade, se constituem como elementos que compõem a identidade cultural do grupo, além de serem artefatos facilitadores de aprendizagem, uma vez que funcionam como mediadores da interação da criança com o mundo. Corroborando, Kishimoto (2016) afirma:

o jogo representa a forma de violar a rigidez dos padrões de comportamentos sociais das espécies. A brincadeira oferece a oportunidade para a criança explorar, aprender a linguagem e solucionar problemas. Educar e desenvolver a criança significa introduzir brincadeiras mediadas pela ação do adulto, sem omitir a cultura, o repertório de imagens sociais e culturais que enriquece o imaginário infantil. (Kishimoto, 2016, p. 15).

É relevante ressaltar que na região Norte, não se costuma observar as quatro estações do ano, somente são bem definidos o inverno e o verão. Em contato com a realidade da comunidade, percebeu-se que algumas brincadeiras dependem das temporadas de inverno e temporadas de verão, por mais que o verão prevaleça na Região Norte, quando é inverno o solo fica permeável, formando poças de lama e como não há sistema de encanação, a água utilizada no dia a dia também vai para o solo, que misturada às pegadas dos animais, dificulta as brincadeiras das crianças.

Foram encontrados também, brinquedos tradicionais no decorrer do convívio cotidiano com o grupo, outros foram apenas relatados. Tais brinquedos estão descritos no quadro 2:

Quadro 2 - Brinquedos na comunidade ribeirinha de Arraiol/AP (2018)

\begin{tabular}{c|c|c|c}
\hline QUAL? & QUANDO? & QUEM? & NOTAS \\
\hline $\begin{array}{c}\text { Boizinhos } \\
\text { de cuia }\end{array}$ & $\begin{array}{c}\text { Antigamente } \\
\text { e hoje }\end{array}$ & crianças & $\begin{array}{c}\text { Para fazer os boizinhos as cuias são } \\
\text { apanhadas ainda pequenas e verdes. }\end{array}$ \\
\hline $\begin{array}{c}\text { Boizinhos } \\
\text { de sementes }\end{array}$ & $\begin{array}{c}\text { Antigamente } \\
\text { e hoje }\end{array}$ & crianças & $\begin{array}{c}\text { Sementes de taperebá, murumuru e } \\
\text { outros. }\end{array}$ \\
\hline
\end{tabular}




\begin{tabular}{|c|c|c|c|}
\hline $\begin{array}{l}\text { Boneca de cacho } \\
\text { de açaí ou de } \\
\text { bacaba }\end{array}$ & $\begin{array}{l}\text { Antigamente e } \\
\text { hoje, mais } \\
\text { raramente }\end{array}$ & $\begin{array}{l}\text { Crianças e } \\
\text { jovens }\end{array}$ & $\begin{array}{l}\text { O topo do caixo é a cabeça e os fios } \\
\text { do caixo são divididos para braços e } \\
\text { pernas }\end{array}$ \\
\hline $\begin{array}{l}\text { Boneca de sabugo } \\
\text { de milho }\end{array}$ & $\begin{array}{l}\text { Antigamente e } \\
\text { hoje mais } \\
\text { raramente }\end{array}$ & crianças & $\begin{array}{c}\text { O sabugo é utilizado } \\
\text { geralmentedepois da retirada do } \\
\text { milho. }\end{array}$ \\
\hline $\begin{array}{l}\text { Barco de casca de } \\
\text { melancia }\end{array}$ & $\begin{array}{c}\text { Antigamente e } \\
\text { hoje mais } \\
\text { raramente }\end{array}$ & crianças & $\begin{array}{l}\text { O corte da boneca é feito de diversas } \\
\text { formas e tamanhos }\end{array}$ \\
\hline $\begin{array}{c}\text { Galinha da flor de } \\
\text { açacú }\end{array}$ & $\begin{array}{l}\text { Antigamente e } \\
\text { hoje mais } \\
\text { raramente }\end{array}$ & crianças & $\begin{array}{c}\text { A flor de uma fruta, virada ao } \\
\text { contrário delineia-se na forma de uma } \\
\text { galinha }\end{array}$ \\
\hline $\begin{array}{l}\text { Barquinho de } \\
\text { isopor }\end{array}$ & Hoje & Crianças & $\begin{array}{c}\text { Geralmente são barquinhos simples, } \\
\text { feitos pelos pais ou pelas próprias } \\
\text { crianças }\end{array}$ \\
\hline $\begin{array}{l}\text { Barquinho de } \\
\text { madeira }\end{array}$ & $\begin{array}{l}\text { Antigamente } \\
\text { e hoje }\end{array}$ & crianças & $\begin{array}{l}\text { Dos mais variados tamanhos, } \\
\text { geralmente feitos pelos pais }\end{array}$ \\
\hline $\begin{array}{l}\text { Carrinhos de lata } \\
\text { de conserva, } \\
\text { sardinha ou óleo }\end{array}$ & $\begin{array}{l}\text { Antigamente } \\
\text { e hoje }\end{array}$ & crianças & $\begin{array}{l}\text { Hoje quase não se vê mais. Não foi } \\
\text { visto durante a visita à comunidade }\end{array}$ \\
\hline Boi de fava & $\begin{array}{l}\text { Antigamente e } \\
\text { hoje mais } \\
\text { raramente }\end{array}$ & crianças & $\begin{array}{c}\text { Favas grandes que geralmente vêm na } \\
\text { maré, são furadas, feitas as perninhas, } \\
\text { as orelhas, e isso forma os bois }\end{array}$ \\
\hline Bóia de aninga & $\begin{array}{c}\text { Antigamente e } \\
\text { hoje mais } \\
\text { raramente }\end{array}$ & $\begin{array}{l}\text { Crianças e } \\
\text { jovens }\end{array}$ & $\begin{array}{l}\text { Há relatos de que era onde as crianças } \\
\text { geralmente aprendiam a nadar }\end{array}$ \\
\hline Bola de aninga & $\begin{array}{l}\text { Antigamente e } \\
\text { hoje mais } \\
\text { raramente }\end{array}$ & $\begin{array}{l}\text { Crianças e } \\
\text { jovens }\end{array}$ & $\begin{array}{c}\text { Relatos de que o material gera } \\
\text { bastante coceira, por isso não é mais } \\
\text { muito utilizado }\end{array}$ \\
\hline $\begin{array}{l}\text { Comida de } \\
\text { matinho }\end{array}$ & $\begin{array}{l}\text { Antigamente } \\
\text { e hoje }\end{array}$ & crianças & $\begin{array}{l}\text { Brincaderia geralmente realizada } \\
\text { pelas meninas }\end{array}$ \\
\hline
\end{tabular}

Fonte: Elaborado pela autora, com base nos dados da pesquisa.

A riqueza cultural infantil é evidente na comunidade. O brincar parte das experiências cotidianas das crianças em suas observações para com os adultos e parte também, na grande maioria das vezes, da utilização de elementos da terra para confecção dos brinquedos. Dewey (1976) sempre acreditava que a verdadeira educação vem unicamente da estimulação dos poderes da criança, partindo das exigências reais, isto é, de situações sociais nas quais ela se encontra. Por intermédio dessas exigências ela é motivada a agir como um componente da integração, a emergir da sua estreiteza de ação e sentimento original e a considerar-se a partir do ponto de vista da coletividade a que ela pertence. Por meio do feedback com as outras pessoas às suas ações, ela passa a saber o que elas significam, em se tratando de fins sociais. $\mathrm{O}$ autor defendia a 
valorização das expressões da infância, o desenvolvimento da criatividade, iniciativa, originalidade, e principalmente a experiência, que nada mais é do que proporcionar um espaço para que as crianças possam ser participantes ativas e ter liberdade de pensamento no decorrer da execução das atividades, conclui o autor.

Com base nos relatos, percebeu-se que algumas brincadeiras sofreram modificações devido ao tempo. Isto é natural, pois os saberes culturais produzidos, não são meras transmissões estáticas resistentes ao tempo; são na verdade um grupo de conhecimentos em constante transformações sociais, que resultam de movimentos históricos e transformações produzidas nas relações humanas com meio ambiente ao longo do tempo. Isso não quer dizer que a comunidade esteja perdendo sua cultura, e sim que ela está em constante movimento. As imagens a seguir evidenciam um pouco dos elementos materiais que são aproveitados para a confecção de brinquedos que são utilizados pelas crianças na comunidade:

Foto 1- Criança com sua rabiola (2018)

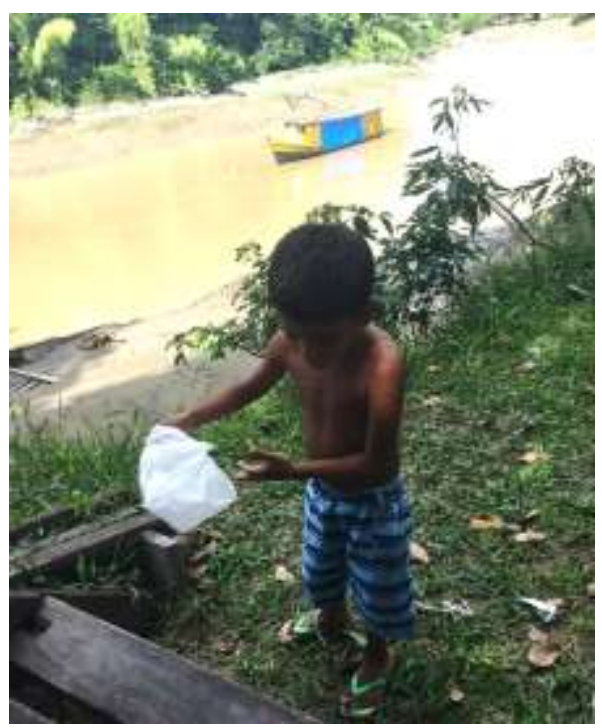

Fonte: acervo das pesquisadoras.
Foto 2- Relato do boi de cuia (2018)

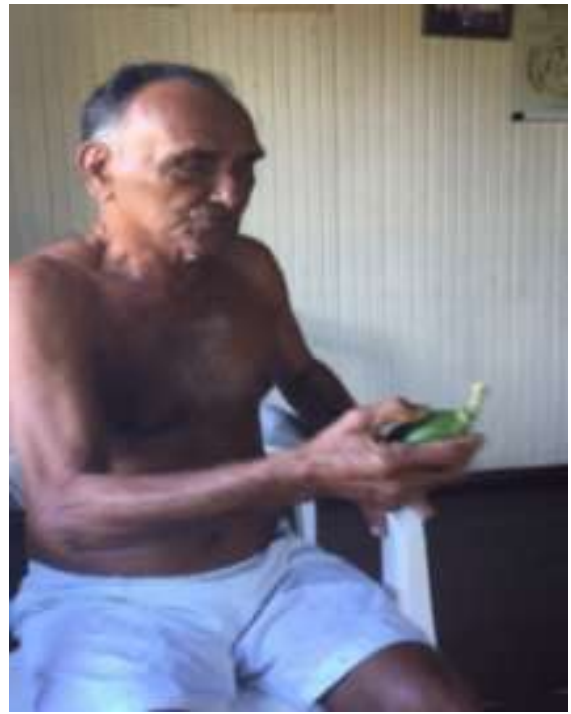

Fonte: acervo das pesquisadoras.

Na foto 1, a criança brinca com uma rabiola, também conhecida como pipa ou papagaio, feita de sacola plástica, que apesar de não ser um elemento material retirado diretamente da Natureza, não deixa de ser um brinquedo feito pela própria criança, que utiliza da sua imaginação, criatividade e originalidade para a constituição da sua brincadeira. Na foto 2, um morador com o fruto da Cueira em mãos, explica uma das formas de como era e ainda são confeccionados os bois que as crianças utilizam em 
suas brincadeiras de curral. Assim, compreende-se que os jogos, brinquedos e brincadeiras tradicionais dos ribeirinhos sofrem modificações ao longo do tempo, mas ainda são formas de mediar o processo de aprendizagem e desenvolvimento da criança por meio das culturas infantis, as quais são características da comunidade ribeirinha que permeia ações através de artefatos sociais e culturais.

\section{Considerações finais}

A proposta deste estudo pautou-se em um trabalho de natureza qualitativa entre pesquisador e a comunidade, objetivado a análise do brincar da criança baseado nos elementos naturais, materiais e imateriais que compõem a cultura local. Os dados preliminares resultantes das primeiras observações diagnósticas comprovaram que a comunidade ainda preserva muitos saberes da terra. Observou-se que o grupo de moradores é bastante organizado, que o brincar é apreciado pelos adultos e que os mesmos percebem a importância da valorização e do pertencimento cultural produzido nas práticas lúdicas, por meio das culturas infantis.

No decorrer do convívio com a comunidade, percebeu-se que as práticas lúdicas das crianças ribeirinhas e as características dessas brincadeiras são específicas do contexto em que as mesmas vivem, sofrendo poucas influências urbanas. As atividades lúdicas foram sendo evidenciadas, comprovando um ambiente rico e uma infância atuante, caminhando na perspectiva do brincar com elementos mediadores que contribuem com o processo formativo da criança. Vale ressaltar a importância identitária do trabalho, que contribui com a valorização da tradição nos contextos ribeirinhos, a cidadania e identidade de povo desse lugar, assim como para o respeito à diversidade brasileira.

Ressalta-se aqui também uma profunda aprendizagem das pesquisadoras. Isto porque o trabalho tem contribuído significativamente em sua própria ação-reflexãoação, realizada a partir do contato direto com as crianças e a comunidade, no qual foi possível aprender mais detalhadamente sobre a cultura do povo daquele lugar. $\mathrm{O}$ trabalho também trouxe uma contribuição com os interessados nos estudos sobre a infância, com a busca pela expansão de estudos relacionados ao brincar ribeirinho e sa- 
beres culturais de uma realidade ainda pouco visualizada - a realidade da criança ribeirinha amazônica.

Portanto, a utilização do diálogo acerca da importância da valorização das culturas infantis para a formação da criança e a defesa de que o brincar contribui para uma formação integral, mais profunda e significativa, bem como uma prática que respeita as culturas infantis e valoriza o desenvolvimento integral da criança, agregando o brincar e a edificação do conhecimento, amplia ainda mais as discussões em relação ao processo formativo que o brincar proporciona. A proposta é que esses diálogos sensibilizem, contribuam e despertem a reflexão sobre a relevância de um trabalho educativo, que inclua efetivamente ações do brincar, a emancipação, dialogicidade e a liberdade de expressão das crianças em todo seu processo formativo.

\section{Referências}

BARDIN, Laurence. Análise de Conteúdo. Lisboa, Portugal: Edições 70, 2016.

BRASIL. Instituto Brasileiro de Geografia e Estatística (IBGE). Censo 2010. Disponível em: <https://censo2010.ibge.gov.br/>.

DEWEY, John. Experiência e educação. São Paulo: Companhia Editora Nacional, 1976.

KISHIMOTO, Tizuko Morchida. Jogo, brinquedo, brincadeira e a educação. São Paulo: Cortez, 2016.

LOPES, José Cordeiro dos Santos. Arraiol do Bailique: uma história de resistência cabocla. Macapá, 1 Ed. 2017.

MEIHY, José Carlos Sebe Bom. Manual de História Oral. São Paulo: Loyola, 2002.

OLIVEIRA, Paulo de Salles. O que é brinquedo? São Paulo: Brasiliense, 1984. (Primeiros Passos).

REIS, Daniela Castro dos et al. Um estudo descritivo das brincadeiras em uma comunidade ribeirinha amazônica. Temas em Psicologia, Belém, v. 22, n. 4, p. 745-758, 2014. Disponível em: <file:///C:/Users/Jesus/Desktop/amazinia.pdf>.

ROJAS, Jucimara; FERREIRA, Francys Marizethe N. Santana. Cultura Lúdica formativa para diferentes etnias na região do Pantanal/Aquidauana/MS. Universidade Federal de Mato Grosso do Sul /UFMS, 2013. Disponível em: <https://www.pucsp.br/webcurricu lo/edicoes_anteriores/encontro-pesquisadores/2013/downloads/anais_encontro_201 
3/oral/franchys_marizeth_nascimento_santana_ferreira_jucimara_rojas.pdf>.

SILVA, Claudete do Socorro. Brinquedos de Miriti: educação, identidade e saberes cotidianos. 2012. Dissertação (Mestrado em Educação) - Universidade federal do Pará, Belém, 2012. Disponível em: <file:///C:/Users/Jesus/Desktop/miriti\%202.pdf>. Acesso em: 2 fev. 2018.

; CARVALHO, Nazaré Cristina. A cultura e a educação amazônica na arte dos brinquedos de miriti. EccoS, São Paulo, n. 27, p. 17-32. jan./abr. 2012.

TEDESCO, Elisangela Da Silva França. Infância pantaneira: a percepção de mundo e a constituição de identidade das crianças ribeirinhas. Cáceres-MT, 2016. Disponível em: <http://portal.unemat.br/media/files/PPGEdu/Dissertacoes/Defendidas_2016/Elisang ela_da_Silva_Franca_Tedesco.pdf>

VYGOTSKY, Lev Semenovich. A formação social da mente: o desenvolvimento dos processos psicológicos superiores. 7. ed. São Paulo: Martins Fontes, 2007.

Artigo recebido em agosto de 2018 e aceito em novembro de 2018. 